\title{
Contributions to Climate Research Using the AIRS Science Team Version-5 Products
}

\author{
Joel Susskind, NASA Goddard Space Flight Center, Greenbelt, MD, USA 20771 \\ Gyula Molnar, Morgan State University/GESTAR \\ Lena Iredell, Science Applications International Corporation
}

\begin{abstract}
This paper compares recent spatial anomaly time series of OLR (Outgoing Longwave Radiation) and OLR CLR $_{\text {(Clear Sky }}$ OLR) as determined using CERES and AIRS observations over the time period September 2002 through June 2010. We find excellent agreement in OLR anomaly time series of both data sets in almost every detail, down to the ${ }^{\circ} \mathrm{x} 1^{\circ}$ spatial grid point level. This extremely close agreement of OLR anomaly time series derived from observations by two different instruments implies that both sets of results must be highly stable. This agreement also validates to some extent the anomaly time series of the AIRS derived products used in the computation of the AIRS OLR product. The paper then examines anomaly time series of AIRS derived products over the extended time period September 2002 through April 2011. We show that OLR anomalies during this period are closely in phase with those of an El Niño index, and that

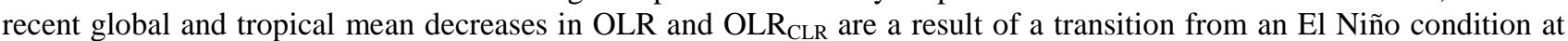
the beginning of the data record to La Niña conditions toward the end of the data period. This relationship can be explained by temporal changes of the distribution of mid-tropospheric water vapor and cloud cover in two spatial regions that are in direct response to El Niño/La Niña activity which occurs outside these spatial regions.
\end{abstract}

Keywords: Satellite meteorology, OLR, climate, ENSO, water vapor, clouds

\section{INTRODUCTION}

OLR (Outgoing Longwave Radiation) is a critical component of the Earth's radiation budget and represents the total radiation going to space emitted by the earth-atmosphere system and integrated over all angles. OLR CLR $_{\text {represents the }}$ Outgoing Longwave Radiation going to space under cloud free conditions. OLR products have been generated and monitored globally since 1975 based on broad spectral band measurements taken at a given satellite zenith angle by the ERB instrument on the Nimbus-6 and Nimbus-7 satellites, the AVHRR instrument on NOAA operational satellites; and most recently by CERES which has flown on EOS Terra since 2000 and EOS Aqua since 2002.

OLR at a given location is affected primarily by the earth's skin surface temperature, skin surface spectral emissivity, atmospheric vertical temperature profile and water vapor profile, and the heights, amounts, and spectral emissivities of multiple layers of cloud cover. OLR can be computed given all the needed geophysical parameters using an OLR Radiative Transfer Algorithm (RTA). Mehta and Susskind developed such an OLR RTA used in conjunction with the TOVS (TIROS Operational Vertical Sounder) retrieval methodology (Susskind et al. 1997) in order to generate the TOVS Pathfinder Path-A OLR data set (Mehta and Susskind 1999a, 1999b). AIRS OLR is computed using AIRS/AMSU sounding products in a completely analogous manner, including use of the same Mehta and Susskind OLR RTA

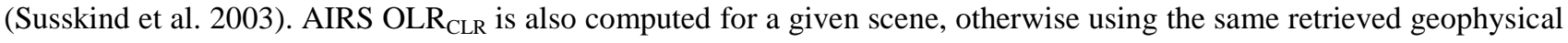
parameters but setting the amount of clouds to be zero. More details about the AIRS Science Team Version-5 OLR products are given in Susskind et al. 2011a and Susskind et al. 2011b.

\section{AIRS AND CERES OLR DATS SETS USED}

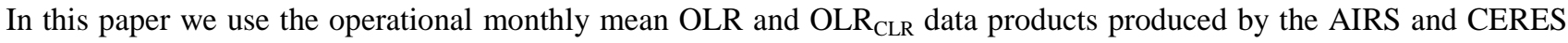
Science Teams respectively. We obtained those AIRS OLR products from the Goddard DISC and the CERES products from the Langley ASDC. AIRS was launched on the EOS Aqua satellite in a 1:30 AM/PM local crossing time orbit in 
May 2002. The operational processing of AIRS data began after AIRS became stable in September 2002. We use the AIRS Version-5 monthly mean Level-3 $1^{\circ} \times 1^{\circ}$ latitude-longitude grid products which contain separate products generated for each of the 1:30 AM and PM local time orbits. We averaged the AM and PM products together to generate and use a single monthly mean product on the $1^{\circ} \mathrm{x} 1^{\circ}$ grid for each month included in the data set. In addition to AIRS

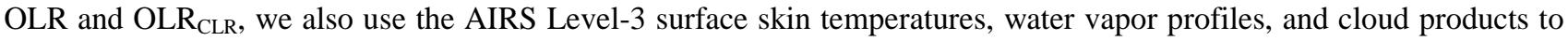
demonstrate the factors contributing to the anomaly time series of OLR and OLR $R_{\text {CLR }}$.

CERES has flown on both EOS Terra, which was launched in December 1999 on a 10:30 AM/PM local crossing time orbit, as well as on EOS Aqua, the same platform that carries AIRS. The CERES Science Team generates a number of different OLR data sets using CERES observations. The latest versions of the longest record CERES OLR data sets are referred to as the CERES SSF1deg-lite Edition-2.5 data sets, which like AIRS, are presented on $1^{\circ} \mathrm{x} 1^{\circ}$ latitude-longitude grid. CERES SSF1deg-lite Edition-2.5 uses the latest calibration improvements with Edition-2 CERES cloud retrievals (Minnis et al. 2008, Minnis et al. 2011), angular dependence models (Loeb et al. 2005), and time-space averaging (Young et al. 1998). At the time of this writing, the CERES Terra Edition-2.5 OLR data sets extended to June 2010, the CERES Aqua Edition-2.5 OLR data sets extended to February 2010, and the AIRS Level-3 products extended to April 2011. For this reason, we chose to compare anomaly time series of AIRS OLR and OLR $\mathrm{CLR}_{\text {with }}$ those obtained from CERES Terra.

\section{GLOBAL MEAN AND TROPICAL MEAN ANOMALY TIME SERIES}

We generated AIRS and CERES monthly mean OLR and OLR $\mathrm{CLR}_{\text {R }}$ climatologies on a $1^{\circ} \mathrm{x} 1^{\circ}$ spatial resolution for each month by taking the average of the grid box value for that month over a 7-year time period. OLR and OLR $\mathrm{CLR}_{\text {anomalies }}$ for a given month in a given year, on a $1^{\circ} \times 1^{\circ}$ spatial grid, are defined as the difference between their monthly mean values and their monthly climatologies for that grid box. The area mean anomaly for a given month is the cosine latitude weighted average of the grid box anomalies contained in the area under consideration.

Figure 1a shows the global mean anomaly time series of AIRS Version-5 OLR and CERES Terra OLR for the periods September 2002 through April 2011 and September 2002 through June 2010, respectively, as well as the difference between the two sets of monthly mean anomalies for the overlap time period. Figure $1 \mathrm{~b}$ shows analogous results for tropical mean OLR anomalies, and Figures 2a and 2b show analogous global mean and tropical mean anomaly time

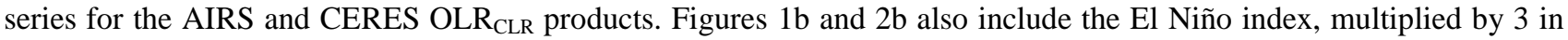
Figure $1 \mathrm{~b}$ and by 2 in Figure 2b. The AIRS El Niño index represents the monthly mean oceanic sea surface temperature (SST) anomaly determined using the AIRS Version- $5 \mathrm{~T}_{\text {skin }}$ product, averaged over the spatial area $15^{\circ} \mathrm{N}$ to $15^{\circ} \mathrm{S}$ latitude and $140^{\circ} \mathrm{W}$ westward to $160^{\circ} \mathrm{E}$ longitude. Tropical mean OLR and OLR anomalies tend to track those of the El Niño

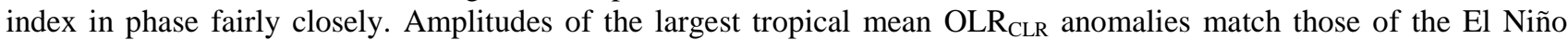
index multiplied by 3, and those of $\mathrm{OLR}_{\mathrm{CLR}}$ anomalies match the El Niño index multiplied by 2. This shows that the greatest tropical mean OLR anomalies are roughly 50\% larger than the greatest tropical mean OLR $_{\text {CLR }}$ anomalies. Positive values of the El Niño index (2003, 2005, 2007, early 2010) correspond to El Niño periods, and negative values (2008, late 2010) correspond to La Niña periods.

Figures 1a and 1b show that an onset of negative global mean OLR anomalies began in late 2007, with tropical mean anomalies generally considerably larger than global mean anomalies, especially after mid-2007. The decrease in global mean OLR in late 2007 is strongly influenced by the significant reduction in tropical mean OLR which started a few months earlier. Tropical mean OLR anomalies, and to a lesser extent global mean OLR anomalies, became positive starting in late 2009, roughly coincident with the onset of another El Niño event. The AIRS OLR product, which extends to April 2011, shows that very substantial negative global and tropical mean OLR anomalies occurred in the period starting mid-2010, in which a substantial La Niña event occurred which continues through the time period observed by AIRS shown in this paper. Figures $2 \mathrm{a}$ and $2 \mathrm{~b}$ show analogous features to those in Figure 1 . We define the Average Rate of Change (ARC) of an anomaly time series as the slope of the linear least squares fit of the time series. The ARC of the El Niño index, computed over the extended time period through April 2011, is $-0.11 \mathrm{~K} / \mathrm{yr}$, which indicates that on the average, the El Niño region has been cooling over the last 8 years. 
September 2002 through April 2011

Global OLR Anomaly Time Series

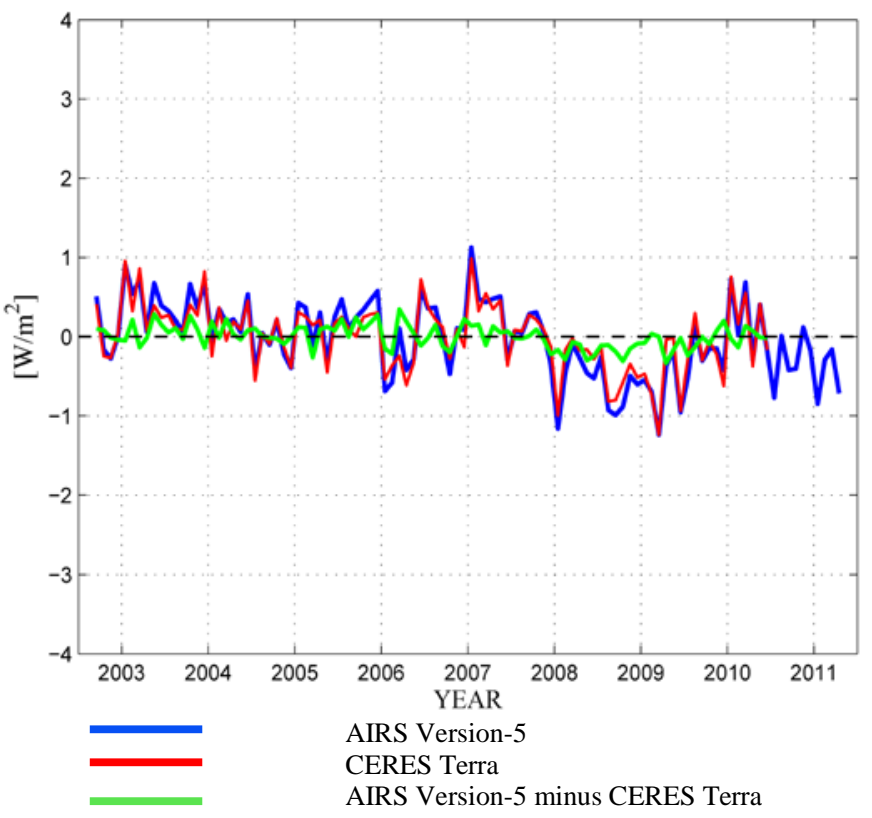

Fig. 1a. Global mean AIRS and CERES Terra monthly mean OLR anomaly time series and their anomaly differences for the overlap period September 2002 through June 2010.

September 2002 through April 2011

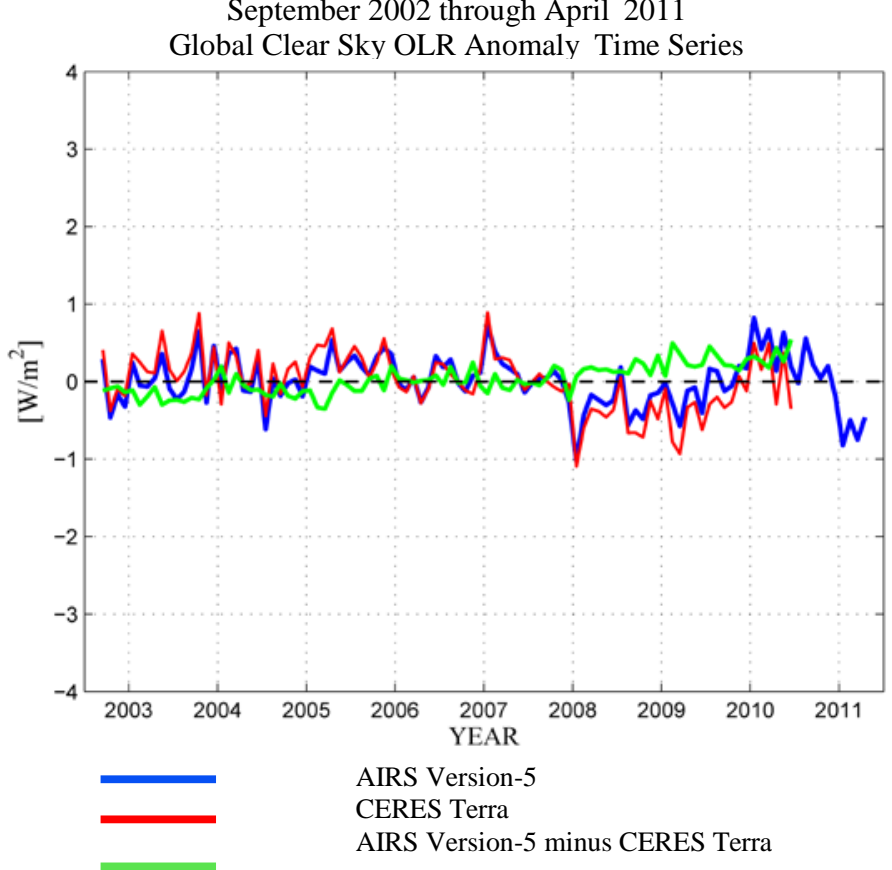

Fig. 2a. Global mean monthly mean OLR $_{\text {CLR }}$ anomaly time series and anomaly differences of AIRS and CERES Terra for the overlap period September 2002 through June 2010.
September 2002 through April 2011

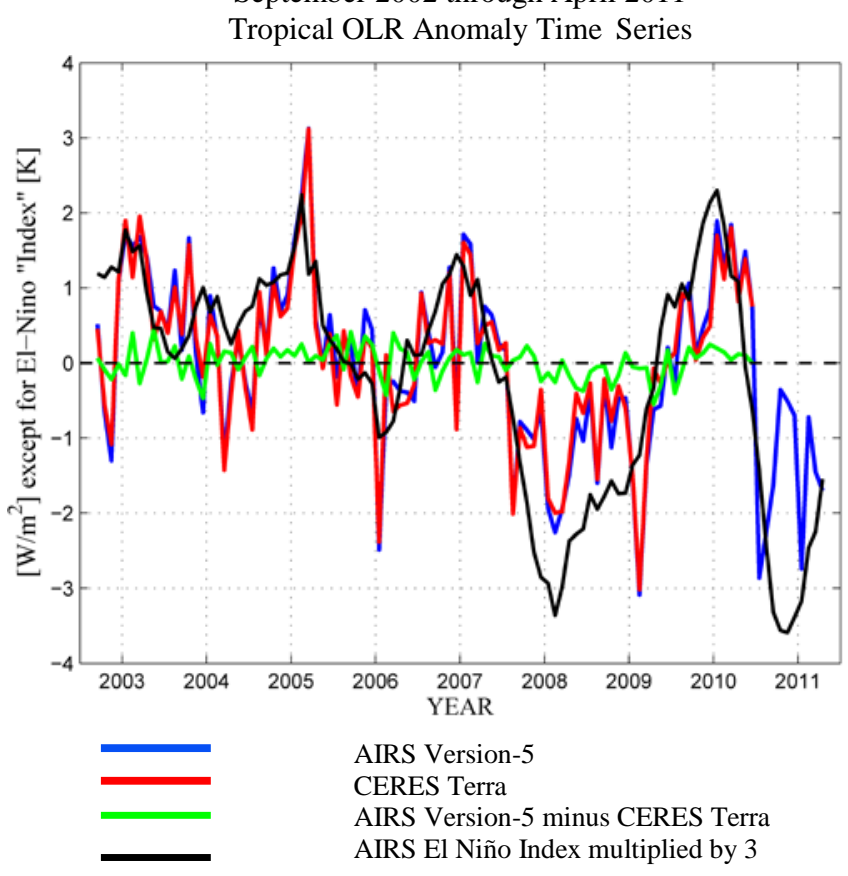

Fig. 1 b. Tropical $\left(20^{\circ} \mathrm{N}\right.$ to $\left.20^{\circ} \mathrm{S}\right)$ mean monthly mean OLR anomaly time series and anomaly differences of AIRS and CERES Terra for the overlap period September 2002 through June 2010. Also shown in black is the AIRS El Niño index multiplied by 3 .

September 2002 through April 2011

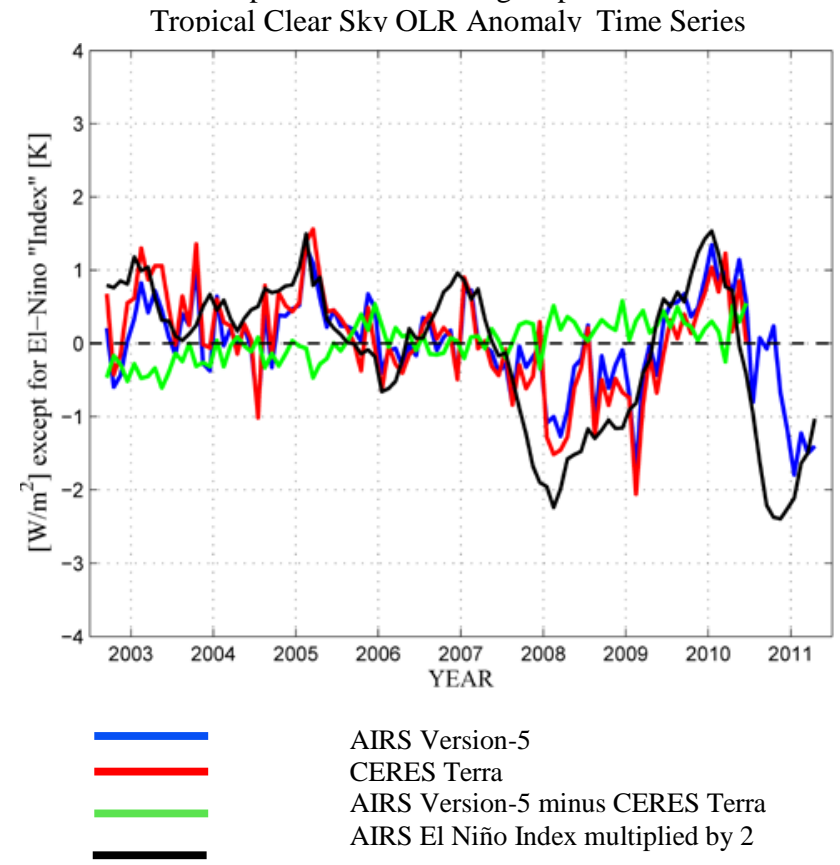

Fig. 2b. Tropical $\left(20^{\circ} \mathrm{N}\right.$ to $\left.20^{\circ} \mathrm{S}\right)$ mean monthly mean $\mathrm{OLR}_{\mathrm{CLR}}$ anomaly time series and anomaly differences of AIRS and CERES Terra for the overlap period September 2002 through June 2010. Also shown in black is the AIRS El Niño index multiplied bv 2. 
Table 1a shows the global and tropical mean values of the ARC's of AIRS OLR and CERES Terra OLR anomalies over the time period September 2002 through June 2010, the standard deviations between the two sets of global and tropical anomaly time series, and the temporal correlations between each global and each tropical anomaly time series. The agreement of the ARC's of both global mean and tropical mean anomaly time series found in the AIRS and CERES OLR records is very good, with a difference of about $0.02 \mathrm{~W} / \mathrm{m}^{2} / \mathrm{yr}$. The uncertainties shown in this table, and subsequent tables, represent the 99\% confidence interval. The temporal correlations of the two sets of global and tropical OLR anomaly time series are 0.953 and 0.983 respectively. Both show that global mean OLR has decreased on the average on the order of $-0.075 \mathrm{~W} / \mathrm{m}^{2} / \mathrm{yr}$ over the common time period September 2002 through June 2010, and tropical mean OLR has decreased at a rate of roughly $-0.1 \mathrm{~W} / \mathrm{m}^{2} / \mathrm{yr}$ from the beginning of the time period to the end. The close agreement of global and tropical mean ARC's of AIRS and CERES OLR anomaly time series is more significant than the values themselves.

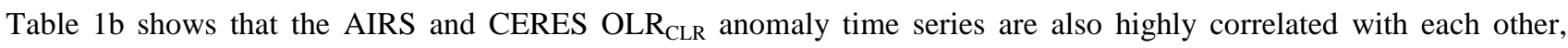
though the correlation is not as high as between the OLR time series. Part of the decrease in correlation is a result of the reduction in values of each set of $\mathrm{OLR}_{\mathrm{CLR}}$ anomalies compared to those of OLR. In addition, the standard deviations of

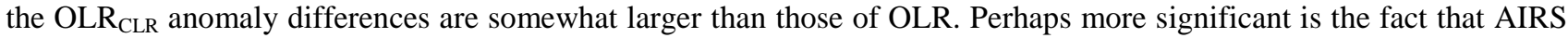

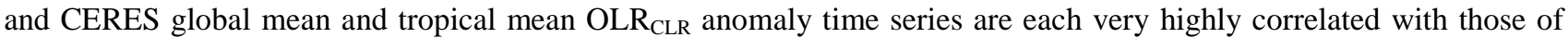
OLR. These and other correlations of anomaly time series are shown in Table 1c which shows temporal correlations between global mean and tropical mean anomaly time series of OLR and OLR $R_{C L R}$ as well as correlations of anomaly time series with the AIRS El Niño index. Correlations using AIRS time series are shown above the diagonal in bold and those using CERES time series are shown beneath the diagonal. The temporal correlation of the CERES global and tropical mean OLR anomaly time series is 0.55 , and the corresponding correlation for the AIRS time series is 0.56 . This shows that tropical anomalies provide a significant contribution to the global OLR anomaly time series. The CERES and AIRS tropical mean OLR anomaly time series also correlate highly with the El Niño index, with temporal correlations of 0.68

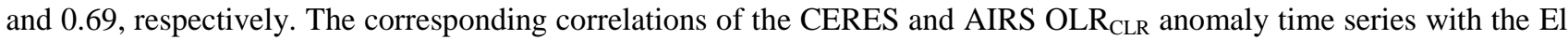
Niño index are 0.70 and 0.63 respectively. Both sets of global OLR and OLR ${ }_{C L R}$ anomaly time series also show moderate correlations with the El Niño index which are smaller than those found in the tropics. These correlations of global and tropical anomaly time series with the El Niño index imply that the recent short term decreases in global and tropical OLR are the result of changes from El Niño conditions at the beginning of the time series to La Niña conditions at the end.

Table 1a. OLR Anomaly Time Series Comparison

September 2002 through June 2010

\begin{tabular}{|c|c|c|}
\hline Data Set & Global & Tropical \\
\hline AIRS ARC $\left(\mathrm{W} / \mathrm{m}^{2} / \mathrm{yr}\right)$ & $-0.0881 \pm 0.0055$ & $-0.1125 \pm 0.0128$ \\
\hline CERES Terra ARC $\left(\mathrm{W} / \mathrm{m}^{2} / \mathrm{yr}\right)$ & $-0.0655 \pm 0.0050$ & $-0.1006 \pm 0.0121$ \\
\hline AIRS Minus CERES STD $\left(\mathrm{W} / \mathrm{m}^{2}\right)$ & 0.147 & 0.210 \\
\hline AIRS/CERES Correlation & 0.953 & 0.983 \\
\hline
\end{tabular}

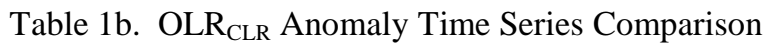

September 2002 through June 2010

\begin{tabular}{|c|c|c|}
\hline Data Set & Global & Tropical \\
\hline AIRS ARC $\left(\mathrm{W} / \mathrm{m}^{2} / \mathrm{yr}\right)$ & $-0.0045 \pm 0.0036$ & $-0.0177 \pm 0.0067$ \\
\hline CERES Terra ARC $\left(\mathrm{W} / \mathrm{m}^{2} / \mathrm{yr}\right)$ & $-0.0703 \pm 0.0043$ & $-0.1018 \pm 0.0078$ \\
\hline AIRS Minus CERES STD $\left(\mathrm{W} / \mathrm{m}^{2}\right)$ & 0.195 & 0.273 \\
\hline AIRS/CERES Correlation & 0.857 & 0.922 \\
\hline
\end{tabular}




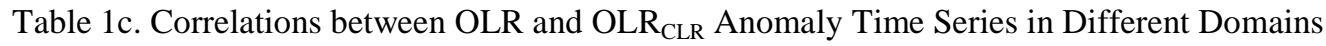

AIRS and CERES

\begin{tabular}{|c|c|c|c|c|c|}
\hline & Global OLR & $\begin{array}{c}\text { Tropical } \\
\text { OLR }\end{array}$ & $\begin{array}{c}\text { Global } \\
\text { OLR }_{\text {CLR }}\end{array}$ & $\begin{array}{c}\text { Tropical } \\
\text { OLR }_{\text {CLR }}\end{array}$ & $\begin{array}{c}\text { El Niño } \\
\text { Index }\end{array}$ \\
\hline $\begin{array}{c}\text { Global } \\
\text { OLR }\end{array}$ & --- & $\mathbf{0 . 5 6}$ & $\mathbf{0 . 7 7}$ & $\mathbf{0 . 4 8}$ & $\mathbf{0 . 4 7}$ \\
\hline $\begin{array}{c}\text { Tropical } \\
\text { OLR }\end{array}$ & 0.55 & --- & $\mathbf{0 . 5 1}$ & $\mathbf{0 . 8 7}$ & $\mathbf{0 . 6 9}$ \\
\hline $\begin{array}{c}\text { Global } \\
\text { OLR }\end{array}$ & 0.79 & 0.56 & --- & $\mathbf{0 . 6 5}$ & $\mathbf{0 . 4 6}$ \\
\hline $\begin{array}{c}\text { Tropical } \\
\text { OLR }_{\text {CLR }}\end{array}$ & 0.55 & 0.87 & 0.73 & --- & $\mathbf{0 . 6 3}$ \\
\hline $\begin{array}{c}\text { El Niño } \\
\text { Index }\end{array}$ & 0.41 & 0.68 & 0.52 & 0.70 & -- \\
\hline
\end{tabular}

\section{THE SPATIAL DISTRIBUTION OF ARC'S}

The spatial distributions of global OLR ARC's over the time period September 2002 through June 2010 are shown in Figures $3 \mathrm{a}$ and $3 \mathrm{~b}$ for AIRS and CERES, respectively. Both fields are presented on the $1^{\circ}$ latitude by $1^{\circ}$ longitude grid on which the data sets are given. Figures $3 a$ and $3 b$ demonstrate two very important points. The first is the virtually indistinguishable spatial distributions of the ARC's of AIRS OLR and of CERES OLR. The spatial correlation of the two sets of ARC's is 0.948 , and the standard deviation of their differences is $0.18 \mathrm{~W} / \mathrm{m}^{2} / \mathrm{yr}$. The second is that there is a considerable longitudinal variation to OLR ARC's at a given latitude, particularly in the tropics. While the tropical mean ARC of OLR is quite negative, areas of very positive OLR ARC's exist in the tropics, particularly near the dateline.

Figures $3 \mathrm{a}$ and $3 \mathrm{~b}$, and some subsequent figures, contain rectangles surrounding the area between $8^{\circ} \mathrm{N}$ to $20^{\circ} \mathrm{S}$ and $140^{\circ} \mathrm{W}$ eastward to $10^{\circ} \mathrm{E}$, which we will refer to as OLR Region 1 , and the area between $15^{\circ} \mathrm{S}$ to $30^{\circ} \mathrm{S}$ and $140^{\circ} \mathrm{E}$ eastward to $160^{\circ} \mathrm{W}$, which we will refer to as OLR Region 2. ARC's of OLR within both these areas are very negative over the period September 2002 through June 2010. The decreases in OLR that took place in these two regions during the period under study will be shown later in the paper to be the major cause of the negative values of the global and tropical mean OLR ARC's shown in Table 1. OLR Regions 1 and 2 were selected entirely based on the results shown in Figure 3 and were chosen both so as to be rectangular and also to encompass key features shown in both Figures 3a and 3b. OLR Region 2 is essentially in the "heart" of the area referred to as the South Pacific Convergence Zone.

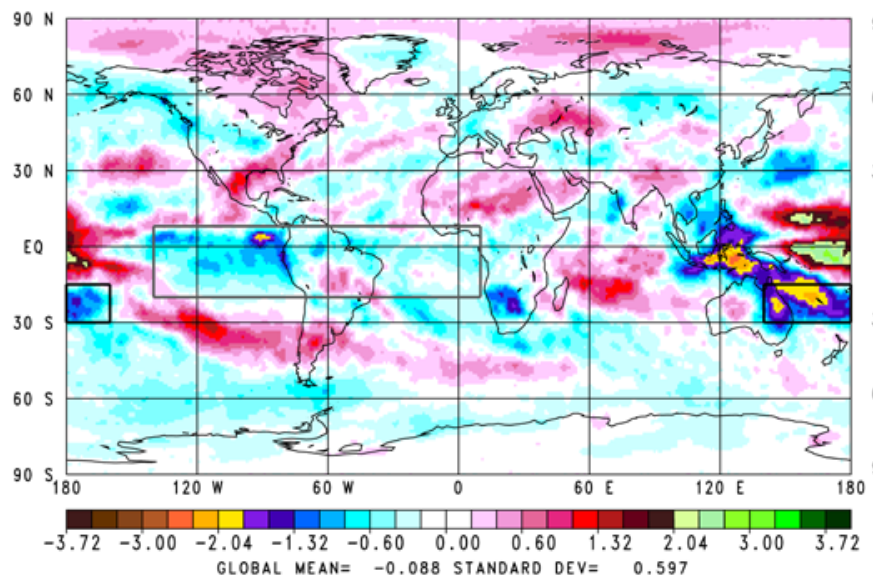

Fig. 3a. Spatial $1^{\circ}$ latitude by $1^{\circ}$ longitude distribution of global AIRS OLR ARC's over the time period September 2002 through June 2010. OLR Region 1 is outlined in gray and OLR Region 2 is outlined in black in this and most subsequent figures showing spatial distributions of ARC's of different parameters.

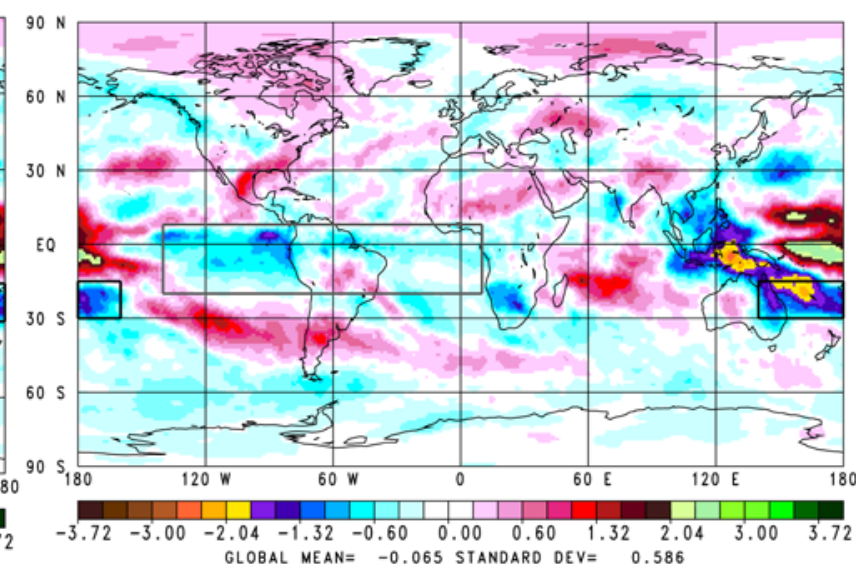

Fig. 3b. Spatial $1^{\circ}$ latitude by $1^{\circ}$ longitude distribution of global CERES OLR ARC's over the time period September 2002 through June 2010 


\section{LONGITUDINAL DISTRIBUTION OF EQUATORIAL ANOMALY TIME SERIES: HOVMÖLLER DIAGRAMS}

Figures 4a and 4b present Hovmöller diagrams, showing time series of monthly mean OLR anomalies (vertical scale), integrated over the latitude range $5^{\circ} \mathrm{N}$ through $5^{\circ} \mathrm{S}$, in each $1^{\circ}$ longitude bin (horizontal scale) for the periods for which AIRS and CERES OLR records exist: September 2002 - April 2011 for AIRS and September 2002 - June 2010 for CERES, and Figure 4c shows their difference. The two sets of Hovmöller diagrams show virtually identical features, including their magnitudes. The spatial temporal correlation between the two sets of Hovmöller diagrams is 0.993. Most of the region covered is ocean. There are three relatively small land areas near the equator: South America, Africa, and Indonesia. These land areas each lie between the three sets of narrow vertical lines shown in Figure 4. There are also two other gray vertical lines at $140^{\circ} \mathrm{W}$ longitude and $10^{\circ} \mathrm{E}$ longitude, encompassing the longitudinal range contained within Region 1. The anomaly time series shown in Figures 4a and $4 \mathrm{~b}$ depict the phase relationship of equatorial OLR anomalies in different longitudes as a function of time. Such figures in turn provide insight into the spatial distribution of tropical ARC's in the vicinity of the equator shown in Figure 3. In the longitudinal band $160 \mathrm{~W}$ westward to $140^{\circ} \mathrm{E}$, equatorial OLR anomalies were very negative in late 2002/early 2003, and were very positive from mid-2007 through early 2009. This gave rise to the substantial positive OLR ARC's shown in Figure 3 over the region $5^{\circ} \mathrm{N}-5^{\circ} \mathrm{S}, 160^{\circ} \mathrm{W}$ to $140^{\circ} \mathrm{E}$. Figure 4a shows that AIRS OLR anomalies in this same region are also very positive starting mid-2010. Therefore, OLR ARC's over the extended time period September 2002 - April 2011 would be even more positive in this area than those shown in Figure 3a covering a shorter time period. Figure 3 shows very negative values of OLR ARC's near the equator between $100^{\circ} \mathrm{E}$ and $140^{\circ} \mathrm{E}$ longitudes. Figure 4 shows that equatorial OLR anomalies between $100^{\circ} \mathrm{E}$ and $140^{\circ} \mathrm{E}$ are out of phase with those between $140^{\circ} \mathrm{E}$ and $160^{\circ} \mathrm{W}$ and are of comparable magnitude. Figures $4 \mathrm{a}$ and $4 \mathrm{~b}$ also show that equatorial OLR anomalies $160^{\circ} \mathrm{W}$ eastward to $40^{\circ} \mathrm{E}$, within the longitudinal domain of OLR Region 1 , tend to

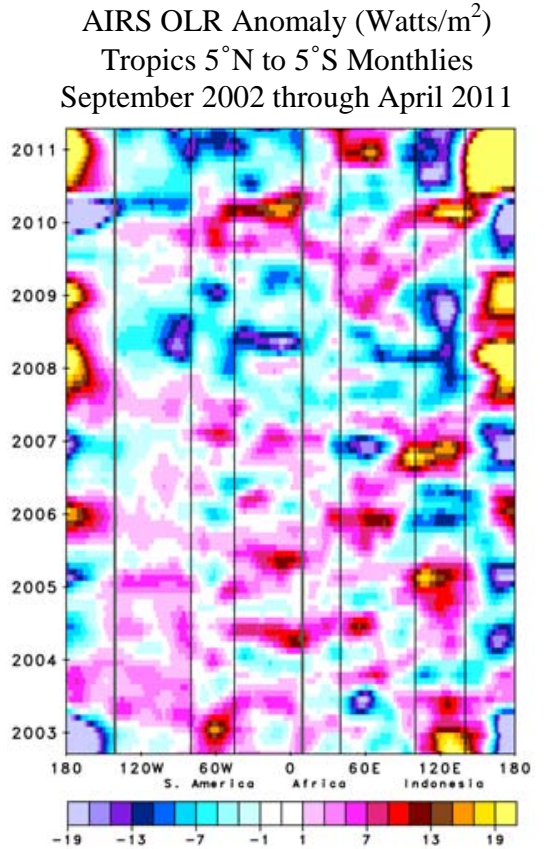

Fig. 4a. Hovmöller diagram for time series of monthly mean AIRS OLR anomalies integrated over the latitude range $5^{\circ} \mathrm{N}$ through $5^{\circ} \mathrm{S}$ in each $1^{\circ}$ longitude bin for the period September 2002 through April 2011. The longitudinal domain of OLR Region 1 is indicated by the gray vertical lines in this and most subsequent Hovmöller diagrams.

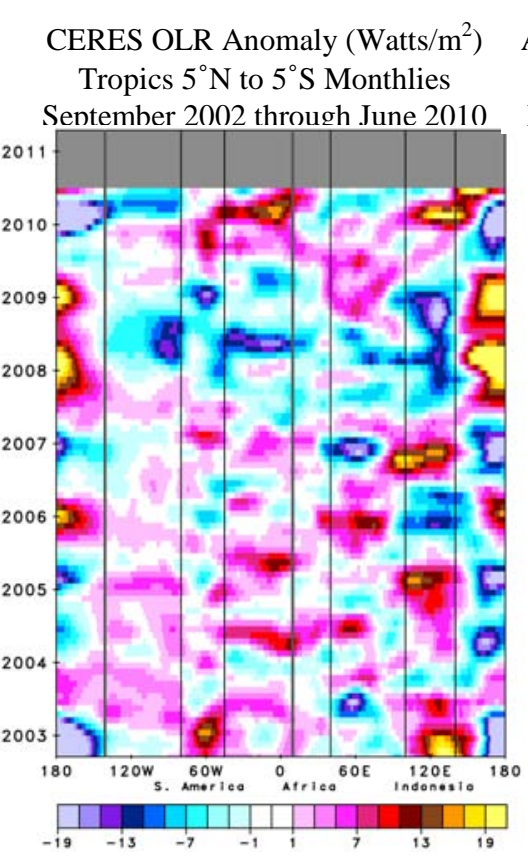

Fig. 4b. Hovmöller diagram for time series of monthly mean CERES OLR anomalies integrated over the latitude range $5^{\circ} \mathrm{N}$ through $5^{\circ} \mathrm{S}$ in each $1^{\circ}$ longitude bin for the period September 2002 through June 2010.
AIRS minus CERES OLR Anomaly (Watts $/ \mathrm{m}^{2}$ ) Tropics $5^{\circ} \mathrm{N}$ to $5^{\circ} \mathrm{S}$ Correlation $=0.993$ Monthlies, September 2002 through June 2010

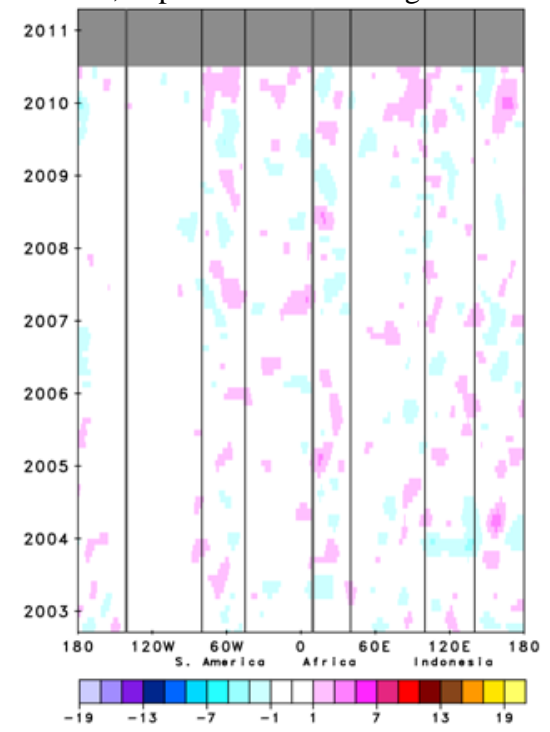

Fig. 4c. Hovmöller diagram for the difference between AIRS OLR and CERES OLR. 
be smaller than, and out of phase with, those from $160^{\circ} \mathrm{W}$ westward to $140^{\circ} \mathrm{E}$. This gives rise to the negative equatorial OLR ARC's shown in Figure 3 in OLR Region 1. Hovmöller diagrams of AIRS and CERES OLR CLR $_{\text {anomalies are very }}$ similar to each other, with a correlation of 0.913 , and are also very similar to those of OLR, but with smaller values of the anomalies.

\section{THE EFFECT OF PHASES OF EL NIÑO/LA NIÑA ON TROPICAL WATER VAPOR, CLOUD COVER, AND OLR ANOMALY TIME SERIES}

Figure 5a shows the spatial distribution of the Average Rate of Change of the AIRS Version 5 surface skin temperature $\mathrm{T}_{\text {skin }}$ over the period September 2002 - April 2011. A number of important features are found in Figure 5a. While the global mean surface skin temperature ARC is essentially zero over this time period, there are areas in which significant positive and negative $\mathrm{T}_{\text {skin }}$ ARC's exist. Both polar regions have warmed over this time period, especially near the North Pole. There is considerable warming and cooling structure in areas over Northern Hemisphere extra-tropical land, and there has been substantial cooling over much of Africa, especially south of $15^{\circ} \mathrm{S}$, as well as over much of Australia. The tropics are marked by a substantial oceanic cooling over the region $15^{\circ} \mathrm{N}$ to $15^{\circ} \mathrm{S}$ and $140^{\circ} \mathrm{W}$ longitude westward to $160^{\circ} \mathrm{E}$ which we refer to as the AIRS El Niño region. The AIRS El Niño region, indicated by the green rectangle in Figure 5a, was defined to encompass the region of large negative sea surface temperature ARC's shown in the figure. There has also been substantial oceanic warming over this time period in the areas to the south, west, and north of the AIRS El Niño region. The AIRS El Niño region as defined in this paper is similar to the commonly used Niño 4 region, $5^{\circ} \mathrm{N}-5^{\circ} \mathrm{S}, 120^{\circ} \mathrm{W}$ westward to $170^{\circ} \mathrm{W}$ (Yeh, et al. 2009).

Figure 5b shows the global distribution of ARC's of $500 \mathrm{mb}$ specific humidity (\%/yr) over the time period September 2002 to April 2011. OLR is very sensitive to the concentration of mid-upper tropospheric water vapor in very moist (i.e. tropical) areas, in the sense that increasing water vapor concentration increases atmospheric absorption in some spectral regions and therefore lowers OLR, everything else being equal. The area of strong equatorial surface temperature cooling in the AIRS El Niño region between $160^{\circ} \mathrm{E}$ and $140^{\circ} \mathrm{W}$, shown in Figure 5a, is marked by a significant mid-tropospheric drying during this period, and the surrounding areas of warming surface skin temperature are marked by considerable mid-tropospheric moistening during the period under study. There is also considerable mid-tropospheric moistening from $8^{\circ} \mathrm{N}$ to $20^{\circ} \mathrm{S}$ in the Atlantic Ocean and especially in the Eastern Pacific Ocean over this time period in areas where there has been at most a very small increase in surface skin temperature. Figures $5 \mathrm{c}$ and $5 \mathrm{~d}$ show ARC's of AIRS OLR and OLR $_{\text {CLR }}$ over the extended time period September 2002 - April 2011. Figures 5b-5d all contain the boundaries of OLR Regions 1 and 2 defined previously. OLR Regions 1 and 2 both correspond to locations in which there has been considerable mid-tropospheric moistening over this time period, as well as considerable decreases in both OLR and OLR $_{\text {CLR }}$.

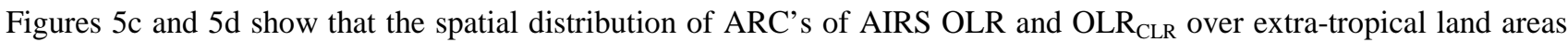
closely track those of $\mathrm{T}_{\text {skin }}$ with areas of warming skin temperatures corresponding to areas of increasing OLR and OLR $_{C L R}$ and vice versa for cooling areas. This demonstrates the expected result that a warming surface should result in increasing flux to space, all other things being held constant. The spatial relationship between ARC's of OLR and $\mathrm{T}_{\text {skin }}$ in the tropics is quite different than in the extra-tropics, especially over ocean. There has been a significant equatorial cooling between September 2002 and April 2011 in the El Niño region surrounding the equator from $160^{\circ} \mathrm{E}$ eastward to $140^{\circ} \mathrm{W}$. This is a reflection of the fact that the time period under study started with an El Niño event in 2002, and had La Niña events in 2007 and 2010. This change from El Niño conditions to La Niña conditions is the driving force behind the recent negative global mean and tropical mean OLR ARC's. The AIRS El Niño region of $\mathrm{T}_{\text {skin }}$ cooling is marked by

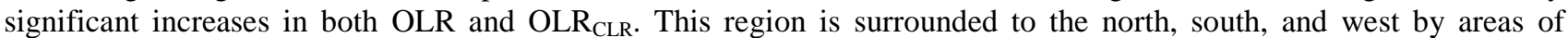
oceanic warming. All of these oceanic areas are marked by large negative OLR ARC's. It is extremely important to note that equatorial OLR also shows large negative ARC's over OLR Region $1,8^{\circ} \mathrm{N}$ to $20^{\circ} \mathrm{S}, 140^{\circ} \mathrm{W}$ eastward to $10^{\circ} \mathrm{E}$, in which there are no spatially coherent changes with regard to $\mathrm{T}_{\text {skin. }}$. In all of these regions, the changes in atmospheric water vapor, rather than in surface skin temperature, have been more significant contributors to the ARC's of AIRS OLR and OLR $_{\text {CLR }}$ over the extended time period September 2002 - April 2011.

Figure 5d shows that spatial ARC's of clear sky OLR, which to first order are independent of changes in cloud cover, closely match ARC's of OLR poleward of '60both in phase and magnitude. This shows that OLR ARC's at high 
latitudes are not influenced substantially by changes in cloud cover $\alpha \epsilon$. In the tropics, the patterns of the ARC's of OLR and clear sky OLR are also similar to each other, but the magnitudes of the relative ARC's are substantially larger with regard to OLR than OLR CLR. Tropical OLR $_{\text {CLR }}$ ARC's are dominated by those of $500 \mathrm{mb}$ specific humidity $q_{500}$. Tropical OLR ARC's are also affected by changes in specific humidity, but are dominated primarily by those of fractional cloud cover $\alpha \epsilon$. ARC's of fractional cloud cover (not shown) closely match those of $500 \mathrm{mb}$ specific humidity. It is the combination of the effects of anomalies of both tropospheric water vapor and fractional cloud cover that give rise to the anomalies and ARC's of OLR as observed by CERES and confirmed by AIRS.

AIRS Version-5 Surface Skin Temperature Anomaly Average Rate of Change (K/yr) September 2002 through April 2011

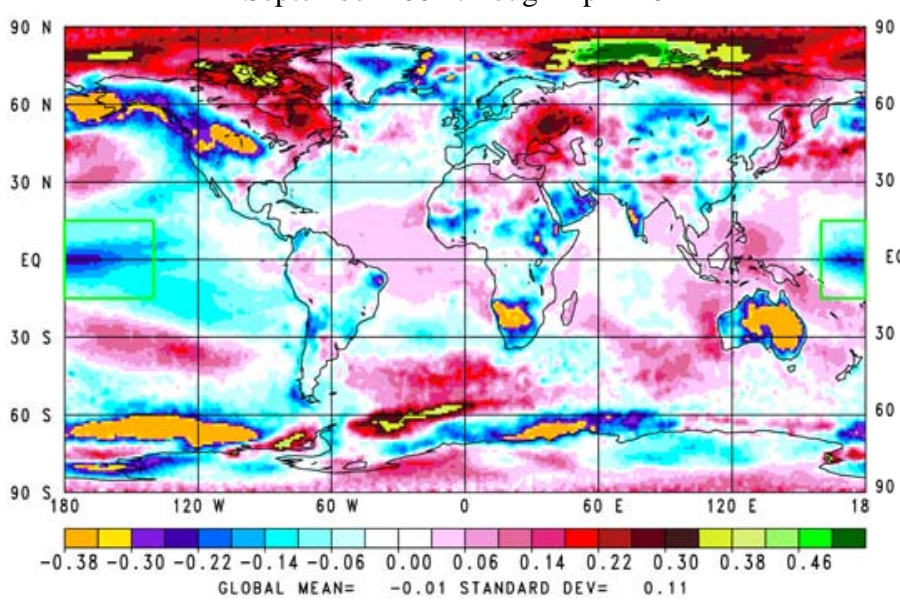

Fig. 5a. Spatial distribution of Average Rate of Change of AIRS surface skin temperature $(\mathrm{K} / \mathrm{yr})$ over the period September 2002 through April 2011. The spatial domain of the AIRS El Niño region is outlined in green.

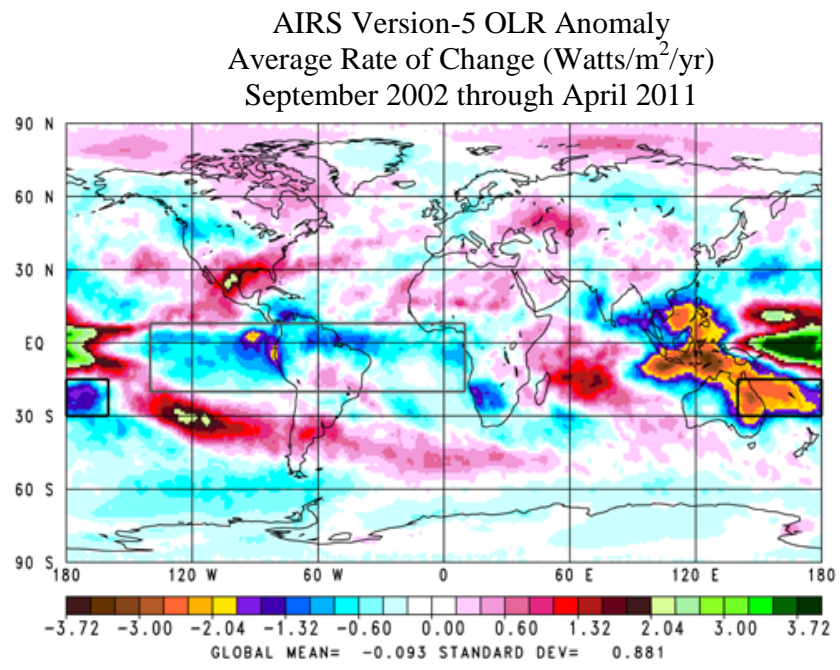

Fig. 5c. Spatial distribution of Average Rate of Change of AIRS OLR $\left(\mathrm{W} / \mathrm{m}^{2} / \mathrm{yr}\right)$ over the period September 2002 through Abril 2011.
AIRS Version-5 500mb Specific Humidity Anomaly Average Rate of Change (\%/yr) September 2002 through April 2011

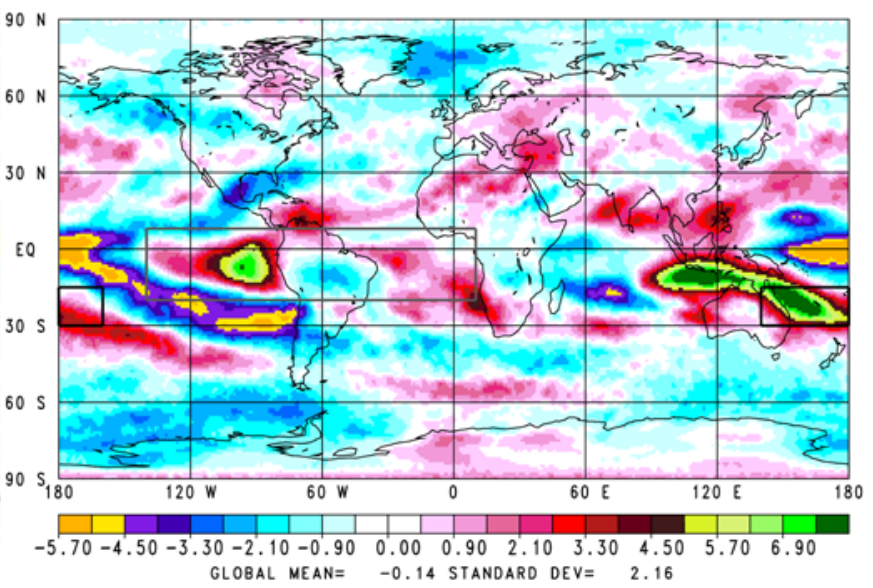

Fig. 5b. Spatial distribution of Average Rate of Change of AIRS $500 \mathrm{mb}$ specific humidity (\%/yr) over the period September 2002 through April 2011.

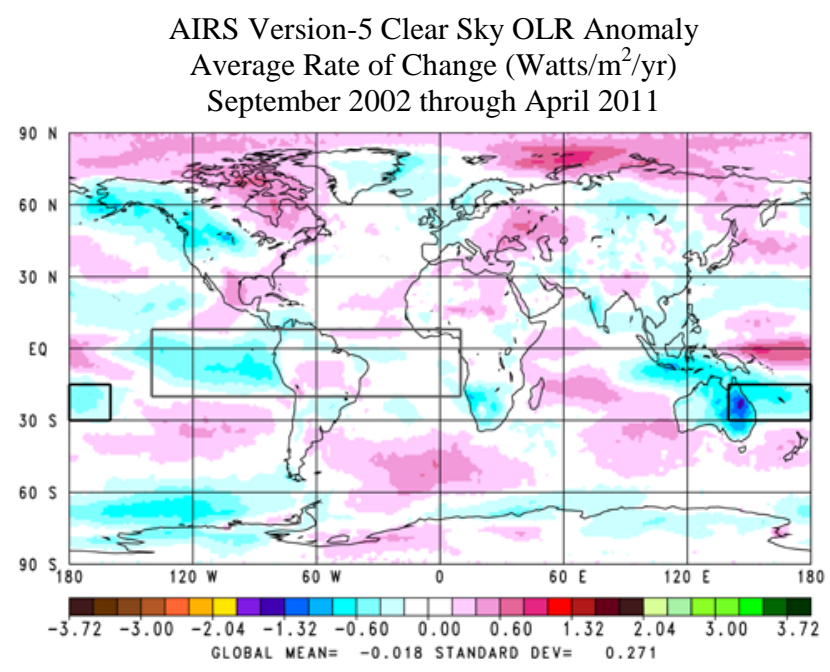

Fig. 5d. Spatial distribution of Average Rate of Change of AIRS Clear Sky OLR (W/ $\left./ \mathrm{m}^{2} / \mathrm{yr}\right)$ over the period September 2002 through April 2011. 
Table 2 shows the spatial correlation of ARC's of OLR, OLR $\mathrm{CLR}_{2}, \alpha \epsilon, \mathrm{q}_{500}$, and $\mathrm{T}_{\text {skin }}$ over the time period September 2002 through April 2011. Spatial correlations of ARC's of these quantities over the latitudinal domain $60 \mathrm{~N}$ through $90^{\circ} \mathrm{N}$ are shown above the diagonal in bold, and analogous spatial correlations over the latitudinal domain $15^{\circ} \mathrm{N}$ through $15^{\circ} \mathrm{S}$ are

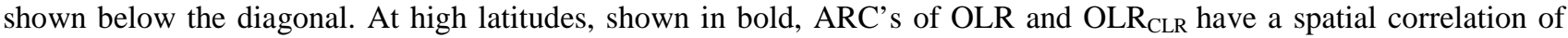
0.83 with each other. Both sets of ARC's are also highly positively correlated with those of $\mathrm{T}_{\text {skin }}$, especially OLR $\mathrm{CLR}_{\text {. }}$. At high latitudes, ARC's of specific humidity and fractional cloud cover are not highly correlated with each other or with any of the other geophysical parameters shown in the table.

Table 2. Spatial Correlations of ARC’s of AIRS Derived Products over the Time Period September 2002 through April 2011

$90^{\circ} \mathbf{N}$ to $60^{\circ} \mathrm{N}$ and $15^{\circ} \mathrm{N}$ to $15^{\circ} \mathrm{S}$

\begin{tabular}{|c|c|c|c|c|c|}
\hline & OLR & OLR $_{\text {CLR }}$ & $\alpha \epsilon$ & $\mathrm{q}_{500}$ & $\mathrm{~T}_{\text {skin }}$ \\
\hline OLR & --- & $\mathbf{0 . 8 3}$ & $\mathbf{0 . 0 7}$ & $\mathbf{0 . 2 3}$ & $\mathbf{0 . 7 7}$ \\
\hline OLR $_{\text {CLR }}$ & 0.80 & --- & $\mathbf{0 . 4 3}$ & $\mathbf{0 . 3 6}$ & $\mathbf{0 . 9 1}$ \\
\hline$\alpha \epsilon$ & -0.91 & -0.80 & -- & $\mathbf{0 . 1 1}$ & $\mathbf{0 . 4 4}$ \\
\hline $\mathrm{q}_{500}$ & -0.81 & -0.82 & 0.69 & --- & $\mathbf{0 . 3 3}$ \\
\hline $\mathrm{T}_{\text {skin }}$ & -0.45 & -0.08 & 0.26 & 0.43 & --- \\
\hline
\end{tabular}

Spatial correlations of ARC's of the same geophysical parameters in the tropics, shown below the diagonal, are very different from those at high latitudes. The correlation of ARC's of OLR and OLR $\mathrm{CLR}_{\text {in }}$ ine tropics is again very high (0.80). In the North Polar region, the high correlation of ARC's of OLR and OLR CLR arose because the spatial

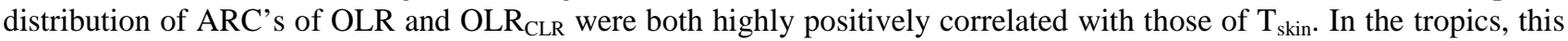

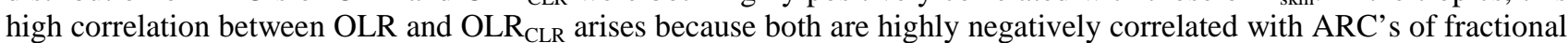
cloud cover $\alpha \epsilon$ and $500 \mathrm{mb}$ specific humidity $\mathrm{q}_{500}$. Unlike at high latitudes, ARC's of tropical $\mathrm{T}_{\text {skin }}$ are not highly correlated with those of any other of the geophysical parameters studied. Tropical correlations of ARC's and OLR and OLR $_{\text {CLR }}$ with those of $T_{\text {skin }}$ are actually somewhat negative because tropical correlations of $T_{\text {skin }}$ with those of $\alpha \epsilon$ and $q_{500}$

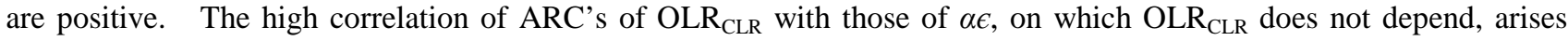
because ARC's of $\alpha \epsilon$ and $q_{500}$ are themselves highly positively correlated with each other.

Figure 6a shows the Hovmöller diagram of monthly mean $\mathrm{T}_{\text {skin }}$ anomalies for the period September 2002 through April 2011. The vertical green lines delineate the longitudinal band included in the El Niño region, $160^{\circ} \mathrm{E}$ longitude eastward to $140^{\circ} \mathrm{W}$ longitude. The largest SST anomalies tend to occur on either side of the dateline between these longitudinal limits. Figure 6a demonstrates that the large negative SST ARC near the equator extending from about $160^{\circ} \mathrm{E}$ eastward to $140^{\circ} \mathrm{W}$ is the result of the transition from an El Niño at the end of 2002 to La Niñas over the time periods late 2007 through 2008, and especially late 2010 through early 2011. Equatorial $\mathrm{T}_{\text {skin }}$ anomalies between $100^{\circ} \mathrm{E}$ and $140^{\circ} \mathrm{E}$ tend to be smaller than, and of opposite sign to, those in the vicinity of the dateline. This gives rise to the band of weaker positive SST ARC's near the equator from $100^{\circ} \mathrm{E}$ to $140^{\circ} \mathrm{E}$.

Figure 6b shows the Hovmöller diagram of $500 \mathrm{mb}$ specific humidity $\mathrm{q}_{500}$. The vertical gray lines delineate the longitudinal extent of OLR Region 1, extending from $140^{\circ} \mathrm{W}$ eastward to $10^{\circ} \mathrm{E} .500 \mathrm{mb}$ specific humidity anomalies near the dateline in general follow those of SST very closely both in magnitude and in phase. This results from the fact that positive SST anomalies in the El Niño region correspond to periods of increased convection in that area, leading to enhanced moisture of the mid-troposphere. Conversely, negative SST anomalies in the El Niño area correspond to periods of decreased convection (increased subsidence) leading to periods of a drier mid-troposphere. Water vapor anomalies over Indonesia, from roughly $100^{\circ} \mathrm{E}$ to $140^{\circ} \mathrm{E}$, are not only out of phase with those near the dateline, as are those of $\mathrm{T}_{\text {skin, }}$, but are also of comparable magnitude to water vapor anomalies near the dateline. This is the result of the westward shift of the area of maximum convection during La Niña periods from the dateline to Indonesia. This out of phase relationship gives rise to the very substantial positive ARC of $500 \mathrm{mb}$ specific humidity over Indonesia during this time period, as shown in Figure 5b. Figure 5b also shows substantial positive $q_{500}$ ARC's in some tropical locations in 
which no significant changes in $\mathrm{T}_{\text {skin }}$ exist. The most notable of these is off the west coast of South America, in the vicinity of $8^{\circ} \mathrm{N}$ to $20^{\circ} \mathrm{S}$ from $140^{\circ} \mathrm{W}$ eastward to $80^{\circ} \mathrm{W}$, which is a part of OLR Region 1 . There is also another region of positive q $_{500}$ ARC's near the equator going across South America and extending eastward along the Atlantic Ocean to about $10^{\circ} \mathrm{E}$ longitude, also contained within OLR Region 1. Figure $6 \mathrm{~b}$ shows that equatorial water vapor anomalies off the west coast of South America tend to be out of phase with those at the dateline, especially during the large La Niña events in 2007-2008 and 2010-2011. This indicates that La Niña periods of decreased convection near the dateline correspond to periods of increased convection eastward of 140E. The same relationship is found to a lesser extent over the Atlantic Ocean extending to $10^{\circ} \mathrm{E}$ longitude at the eastern end of OLR Region 1.

Figure 6c shows the Hovmöller diagram of the AIRS effective cloud fraction $\alpha \epsilon$. The anomalies of effective cloud fraction averaged over ${ }^{\circ} \mathbb{N}$ to $5^{\circ} \mathrm{S}$ latitude are closely in phase with those of $500 \mathrm{mb}$ specific humidity, with a temporal/spatial correlation of 0.717 . This correlation is a result of the fact that periods of increased convection (or subsidence) correspond to increases (or decreases) of not only mid-tropospheric water vapor but also cloud cover, especially with regard to high clouds. Anomalies of $\mathrm{OLR}_{\mathrm{CLR}}$ are driven primarily by those of $\mathrm{q}_{500}$, and those of OLR are driven primarily by effective cloud fraction, $\alpha \epsilon$, with a smaller contribution from $\mathrm{q}_{500}$. The high correlation between tropical anomalies of OLR and OLR $\mathrm{CLR}_{\mathrm{C}}$ are the result of the correlation between anomalies of $\alpha \epsilon$ and $\mathrm{q}_{500}$.

AIRS Surface Skin Temperature Anomalies (K)

Tropics $5^{\circ} \mathrm{N}$ to $5^{\circ} \mathrm{S}$

Monthlies, September 2002 through April 2011

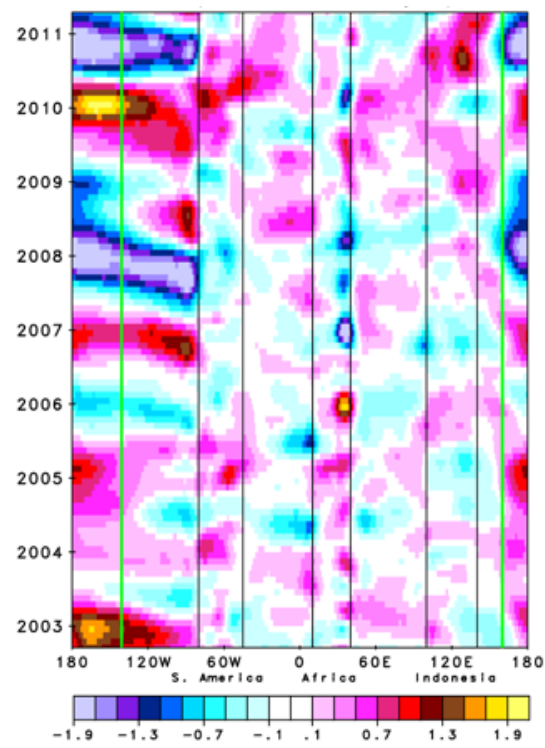

Fig. 6a. Hovmöller diagram of AIRS Surface Skin Temperature anomalies (K). The longitudinal domain of the $\mathrm{El}$ Niño region is enclosed between the green vertical lines.
AIRS 500 mb Specific Humidity Anomalies (\%)

Tropics $5^{\circ} \mathrm{N}$ to $5^{\circ} \mathrm{S}$

Monthlies, September 2002 through April 2011

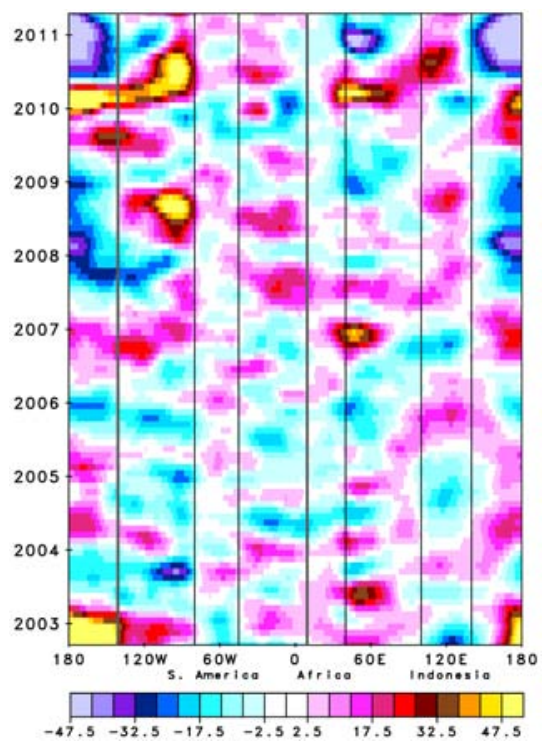

Fig. 6b. Hovmöller diagram of AIRS 500 mb specific humidity anomalies (\%). The longitudinal domain of Region 1 is enclosed between the gray vertical lines.
AIRS Effective Cloud Fraction Anomalies (\%)

Tropics $5^{\circ} \mathrm{N}$ to $5^{\circ} \mathrm{S}$

Monthlies, September 2002 through April 2011

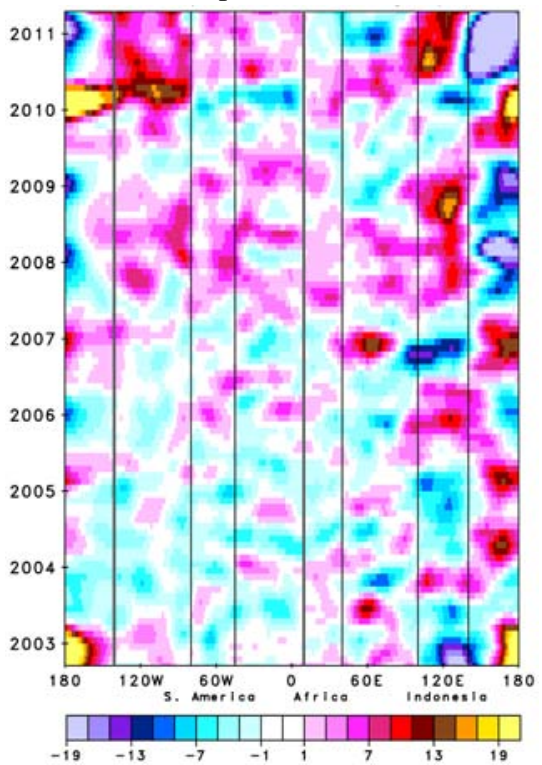

Fig. 6c. Hovmöller diagram of AIRS effective cloud fraction anomalies (\%). The longitudinal domain of Region 1 is enclosed between the gray vertical lines.

Table 3 shows the spatial-temporal correlations of the Hovmöller diagrams of anomalies of OLR, OLR $\mathrm{CLR}_{2}, \alpha \epsilon, \mathrm{q}_{500}$, and $\mathrm{T}_{\text {skin }}$ derived from AIRS observations over the period September 2002 through April 2011. Unlike Table 2, this table is symmetric above and below the diagonal because only one set of correlation statistics is presented. Spatial-temporal anomaly correlations between OLR, OLR $\mathrm{CLR}_{2}, \alpha \epsilon, \mathrm{q}_{500}$, and $\mathrm{T}_{\text {skin }}$ averaged over the latitude range $\mathrm{SN}$ through $5^{\circ} \mathrm{S}$ are extremely close to those shown in the lower half of Table 2, representing spatial correlations of ARC's of these geophysical parameters in the tropics. This shows that not only are the spatial patterns of Average Rates of Change of tropical OLR, OLR $\mathrm{CLR}_{\mathrm{L}}, \alpha \epsilon$, and $\mathrm{q}_{500}$ highly correlated with each other, but the detailed structure of their spatial anomalies as a function of time are highly correlated as well. 
Table 3. Spatial-temporal Correlations of AIRS Anomaly Hovmöller Diagrams $5^{\circ} \mathrm{N}-5^{\circ} \mathrm{S}$ September 2002 Through April 2011

\begin{tabular}{|c|c|c|c|c|c|}
\hline & OLR & OLR $_{\text {CLR }}$ & $\alpha \epsilon$ & $\mathrm{q}_{500}$ & $\mathrm{~T}_{\text {skin }}$ \\
\hline OLR & 1.000 & 0.80 & -0.93 & -0.79 & -0.45 \\
\hline OLR $_{\text {CLR }}$ & 0.80 & 1.000 & -0.77 & -0.72 & -0.05 \\
\hline$\alpha \epsilon$ & -0.93 & -0.77 & 1.000 & 072 & 0.30 \\
\hline $\mathrm{q}_{500}$ & -0.79 & -0.72 & 0.72 & 1.000 & 0.53 \\
\hline $\mathrm{T}_{\text {skin }}$ & -0.45 & -0.05 & 0.30 & 0.53 & 1.000 \\
\hline
\end{tabular}

\section{ATTRIBUTION OF RECENT DECREASES IN GLOBAL AND TROPICAL MEAN OLR TO CHANGES CONTAINED WITHIN OLR REGIONS 1 AND 2}

Figure 7a shows the AIRS OLR anomaly time series averaged over OLR Region 1 in dark blue. Figure 7a also includes in black the El Niño index, this time multiplied by 4, rather than multiplied by 3 as was done in Figure 1b. The Region 1 OLR anomaly time series closely follows that of the El Niño index, but is lagged in time (El Niño occurs first) by about 3 months. Therefore, in Figure 7a, Region 1 OLR anomalies are plotted 3 months earlier than they actually occurred. For this reason, the dark blue line starts 3 months before the black line, and also ends 3 months earlier than the black line. The correlation coefficient of the 3 month lagged Region 1 OLR anomaly with that of the El Niño index is 0.898. Figure 7 a also contains the anomaly time series of OLR $_{C L R}$ averaged over Region 1, shown by the light blue line, which like the

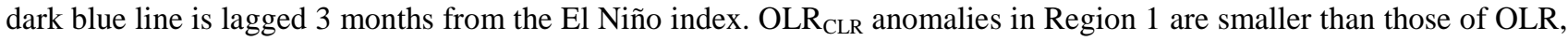
but are highly correlated with those of OLR, with a correlation coefficient of 0.873 . The 3 month lagged OLR CLR anomalies are also highly correlated with those of the El Nino index, with a correlation of 0.821 .

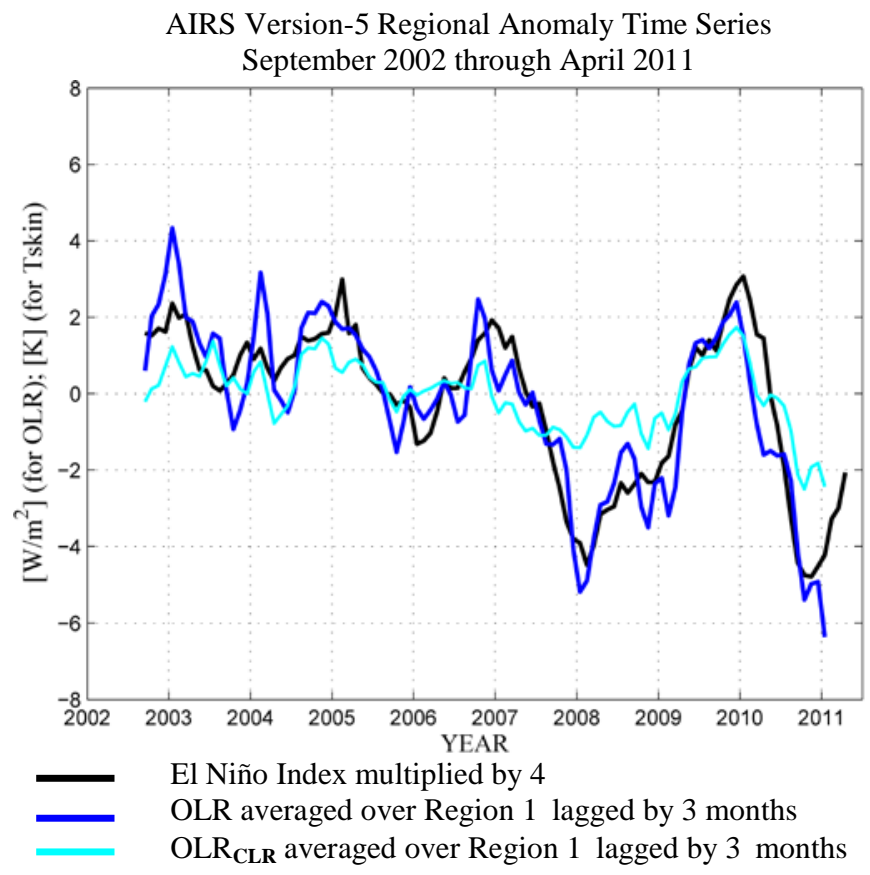

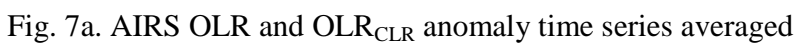
over OLR Region 1 superimposed on the AIRS El Niño index multiplied by 4 and plotted 3 months earlier.

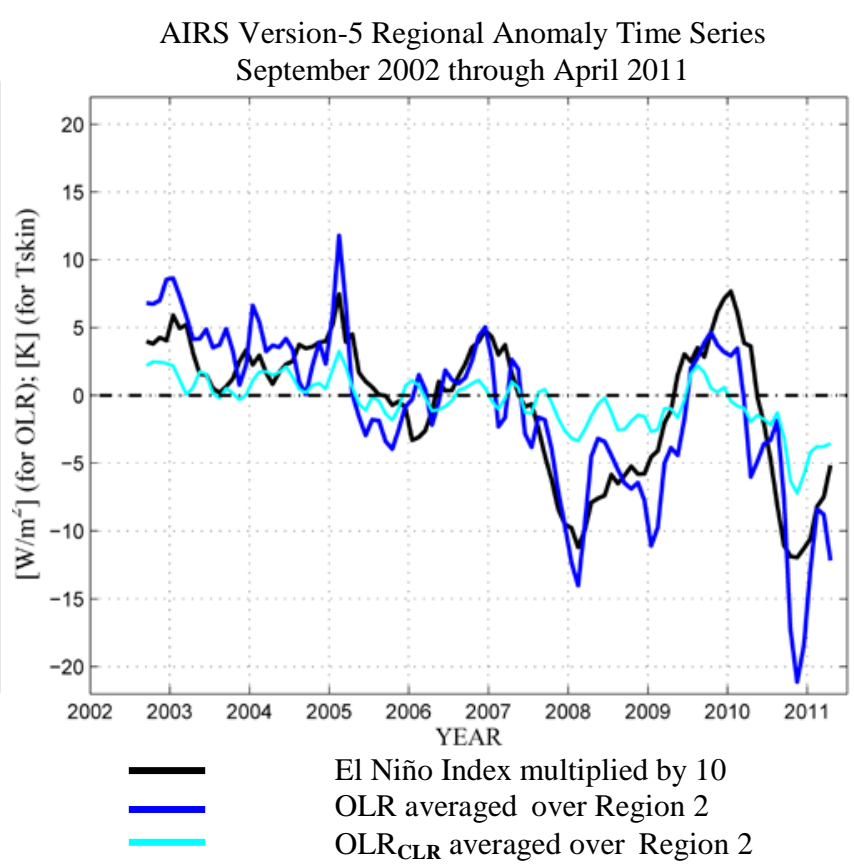

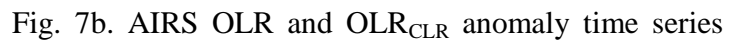
averaged over OLR Region 2 superimposed on the AIRS El Niño index multiplied by 10 without a time lag. 


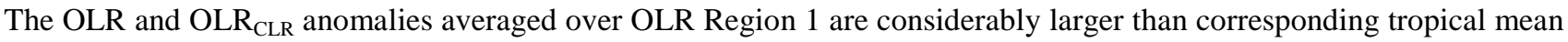

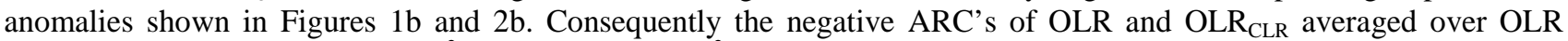
Region 1 , which are $-0.530 \mathrm{~W} / \mathrm{m}^{2} \mathrm{yr}$ and $-0.150 \mathrm{~W} / \mathrm{m}^{2} / \mathrm{yr}$ respectively, are considerably larger than the corresponding negative ARC's of tropical mean OLR and OLR $_{\text {CLR }}$ given by $-0.188 \mathrm{~W} / \mathrm{m}^{2} / \mathrm{yr}$ and $-0.074 \mathrm{~W} / \mathrm{m}^{2} / \mathrm{yr}$. These values are included in Table 4, which shows area mean Average Rates of Change of the AIRS anomaly time series of OLR and OLR $_{\text {CLR }}$, computed over the time period September 2002 through April 2011, averaged over different spatial domains. The negative tropical mean OLR ARC over the period September 2002 through April 2011 computed as previously, but after replacing OLR ARC's in OLR Region 1 by zeroes, is reduced from $-0.188 \mathrm{~W} / \mathrm{m}^{2} / \mathrm{yr}$ to $-0.032 \mathrm{~W} / \mathrm{m}^{2} / \mathrm{yr}$, and the negative global mean OLR ARC is reduced from $-0.093 \mathrm{~W} / \mathrm{m}^{2} / \mathrm{yr}$ to $-0.039 \mathrm{~W} / \mathrm{m}^{2} / \mathrm{yr}$. When an analogous procedure is done with regard to $\mathrm{OLR}_{\mathrm{CLR}}$, the negative tropical mean $\mathrm{OLR}_{\mathrm{CLR}} \mathrm{ARC}$ is reduced from $-0.074 \mathrm{~W} / \mathrm{m}^{2} / \mathrm{yr}$ to -0.030 $\mathrm{W} / \mathrm{m}^{2} / \mathrm{yr}$ and the negative global mean ARC of $\mathrm{OLR}_{\mathrm{CLR}}$ is reduced from $-0.018 \mathrm{~W} / \mathrm{m}^{2} / \mathrm{yr}$ to $-0.003 \mathrm{~W} / \mathrm{m}^{2} / \mathrm{yr}$. This indicates that a large part of the recent negative global mean and tropical mean OLR and OLR ${ }_{\text {CLR }}$ ARC's results from the

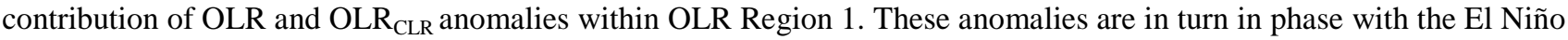
index, but lagged in time by roughly 3 months. It is for this reason that the global and tropical OLR and OLR $\mathrm{CLR}_{\text {anomaly }}$ time-series shown in Figures 1 and Figure 2 are in phase with, and highly correlated with, El Niño/La Niña activity as noted earlier.

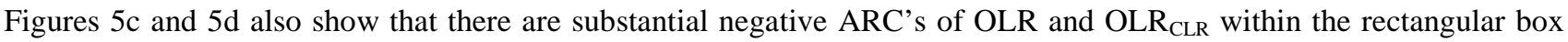
surrounding the area from $15^{\circ} \mathrm{S}$ to $30^{\circ} \mathrm{S}$ and westward from $150^{\circ} \mathrm{W}$ to $140^{\circ} \mathrm{E}$, referred to as OLR Region 2. One-third of this region is in the tropics and the remaining two-thirds is in the subtropics. OLR Region 2 is also marked by large positive ARC's of mid-tropospheric water vapor, as shown in Figure 5b, and cloud cover (not shown) over the period under study. Figure $7 \mathrm{~b}$ shows in dark blue and light blue the time series of OLR anomalies and OLR $\mathrm{CLR}_{\text {anomalies in }}$ OLR Region 2, superimposed on the time series of the El Niño index, this time multiplied by 10, without a time lag. As shown in Table 4, OLR in Region 2 has an extremely large negative ARC of $-1.74 \mathrm{~W} / \mathrm{m}^{2} / \mathrm{yr}$, and $\mathrm{OLR}_{\mathrm{CLR}}$ in Region 2 has a very large negative ARC of $-0.54 \mathrm{~W} / \mathrm{m}^{2} / \mathrm{yr}$. All three curves in Figure $7 \mathrm{~b}$ are highly correlated with each other in time. The correlation between the unlagged anomaly time series of the El Niño index and OLR in region 2 is 0.854 , the correlation between the El Niño index and the anomaly time series of OLR $\mathrm{CLR}_{\mathrm{R}}$ in Region 2 is 0.781 , and the correlation

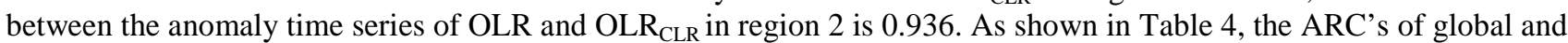

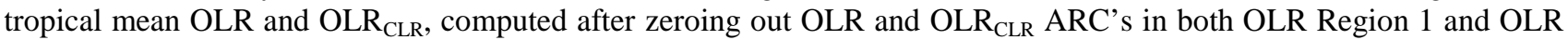
Region 2, are reduced to essentially zero. This shows that the large negative global and tropical ARC's of OLR and OLR $_{\text {CLR }}$ over the period September 2002 through April 2011 can be attributed almost completely to temporal changes in mid-tropospheric water vapor and cloud cover that have taken place primarily within OLR Region 1 along the equator in the eastern Pacific and Atlantic Ocean, with a further contribution from OLR Region 2 primarily in the southern hemisphere subtropics south-southwest of the El Niño region, covering Eastern Australia and parts of the southwestern Pacific Ocean.

Table 4. Area Mean Average Rates of Change of OLR and $\operatorname{OLR}_{\mathrm{CLR}}\left(\mathrm{W} / \mathrm{m}^{2} / \mathrm{yr}\right)$ September 2002 through April 2011

\begin{tabular}{|l|c|c|}
\hline \multicolumn{1}{|c|}{ Spatial Area } & OLR & OLR $_{\text {CLR }}$ \\
\hline Global & $-0.093 \pm 0.0045$ & $-0.018 \pm 0.0031$ \\
\hline Tropical & $-0.188 \pm 0.0111$ & $-0.074 \pm 0.0059$ \\
\hline Region1 & $-0.530 \pm 0.0229$ & $-0.150 \pm 0.0097$ \\
\hline Region 2 & $-1.740 \pm 0.0672$ & $-0.540 \pm 0.0218$ \\
\hline Global excluding Region 1 & $-0.039 \pm 0.0035$ & $-0.003 \pm 0.0026$ \\
\hline Tropical excluding Region 1 & $-0.032 \pm 0.0080$ & $-0.030 \pm 0.0038$ \\
\hline Global excluding Region 1 and 2 & $-0.004 \pm 0.0035$ & $0.008 \pm 0.0026$ \\
\hline Tropical excluding Region 1 and 2 & $0.002 \pm 0.0078$ & $-0.018 \pm 0.0035$ \\
\hline
\end{tabular}




\section{REFERENCES}

[1] Loeb, N.G., Kato, S., Loukachine, K., and Manalo-Smith, N., “Angular Distribution Models for Top-of-Atmosphere Radiative Flux Estimation from the Clouds and the Earth's Radiant Energy System Instrument on the Terra Satellite. Part 1: Methodology,” J. Atmos. Ocean. Tech., 22(4), 338-351.doi:10.1175/JTECH1712.1 (2005).

[2] Mehta, A.V. and Susskind, J., “Outgoing Longwave Radiation from the TOVS Pathfinder Path A Data Set," J. of Geophys. Res., 104, 12193-12212 (1999a).

[3] Mehta, A.V. and Susskind,J., "Longwave Radiative Flux Calculations in the TOVS Pathfinder Path A Data Set," NASA Tech. Rep., GSFC/CR-1999-208643. Proc. SPIE International Symp. Infrared Spaceborne Remote Sensing and Instrumentation XVII, San Diego, CA, August 2009 (1999b).

[4] Minnis, P., Trepte, Q.Z., Sun-Mack, S., Chen, Y., Doelling, D.R., et al., "Cloud Detection in Non-polar Regions for CERES Using TRMM VIRS and Terra and Aqua MODIS Data,” IEEE Trans. Geosci. Remote Sens., 46, 3857-3884 (2008).

[5] Minnis, P., Sun-Mack, S., Young, D.F., Heck, P.W., Garber D.P., et al., "CERES Edition-2 Cloud Property Retrievals Using TRMM VIRS and Terra and Aqua MODIS data. Part 1: Algorithms," IEEE Trans. Geosci. Remote Sens. (in press) (2011).

[6] Susskind, J., Piraino, P., Rokke, L., Iredell, L., and Mehta, A.V., "Characteristics of the TOVS Pathfinder Path A Data Set,” Bull. of Amer. Meteorol. Soc., 78, 1449-1472 (1997).

[7] Susskind, J., Barnet, C.D., Blaisdell, J.M., "Retrieval of atmospheric and surface parameters from AIRS/AMSU/HSB data in the presence of clouds," IEEE Transactions on Geoscience and Remote Sensing, Issue 2, 41, doi: 10.1109/TGRS.2002.808236, 390-409 (2003).

[8] Susskind, J., Blaisdell, J.M., Iredell, L., and Keita, F., "Improved Temperature Sounding and Quality Control Methodology Using AIRS/AMSU Data: The AIRS Science Team Version 5 Retrieval Algorithm. Geoscience and Remote Sensing,” IEEE Transactions on Geoscience and Remote Sensing, Issue: 99 Digital Object Identifier:

10.1109/TGRS.2010.2070508, Publication Year: 2011, 1-25 (2011a).

[9] Susskind, J., Molnar, G., and Iredell, L., "The Effect of El Niño/La Niña Oscillations on Recent Anomaly Time Series of OLR,” Submitted to J. Climate (2011b).

[10] Yeh, S.-W., Kug, J.-S., Dewitte, B., Kwon, M.-H., Kirtman, B.P., and Jin, F.-F., "El Niño in a Changing Climate,” Nature, 461, 511-514, doi:10.1038/nature08316 (2009).

[11] Young, D.F., Minnis, P., Doelling, D.R., Gibson, G.G., and Wong, T., “Temporal Interpolation Methods for the Clouds and the Earth's Radiant Energy System (CERES) Experiment,” Jour. of Applied Meteor., 37(6), 572-590 (1998). 